\title{
Differentiation of Vasospastic Angina from Noncardiac Chest Pain by History and Coronary Risk Factors in Patients with Chest Pain at Rest
}

\author{
Tadafumi Nanbu, Isao Satou, Hirotaka NishiJima* and Akira KitabataKe**
}

\begin{abstract}
To determine the efficacy of the medical interview and the coronary risk factor profile in differentiating vasospastic angina from other causes of chest pain, we examined 59 patients who underwent diagnostic coronary angiography with selective intracoronary injection of acetylcholine. In the medical interview, a questionnaire on the characteristics of chest pain and additional symptoms was given. We examined coronary risk factors from laboratory tests, life history, and physical examination. Chest pain accompanied by cold sweat and occurring in the early morning was the only significant discriminating information; the location of pain and the duration were not discriminating. Classic coronary risk factors did not differ between vasospastic angina and noncardiac chest pain except for gender. We conclude that history taking is the most important means to distinguish vasospastic angina from other causes of chest pain.
\end{abstract}

(Internal Medicine 36: 676-679, 1997)

Key words: coronary vasospasm, chest pain at rest, acetylcholine

\section{Introduction}

There are many patients who visit physicians with the chief complaint of chest pain at rest. The pain may or may not be the manifestation of ischemic heart disease but this symptom is one of the most common reasons for cardiac consultations. Although cardiologists often need to rule out vasospastic angina, the efficacy of noninvasive tests in making a diagnosis is limited if the attacks of chest pain occur infrequently. The gold standard for the presence of vasospastic angina is the presence of cardiac ischemia with a demonstration of coronary spasm on coronary angiography. But it is not practical to perform coronary angiography in all suspected patients.

Clinically, history remains the most important means for distinguishing among many other causes of chest pain. Detailed and thoughtful history often reveals the etiology of chest pain. Though the importance of history taking has been emphasized (1), it is not clear whether it is applicable to chest pain at rest. When history taking is not determinative, coronary risk factors are important to help decide the indication for coronary angiography. But it is not well known whether the absence of coronary risk factors support the absence of vasospastic angina.

The aim of this study was to differentiate vasospastic angina from noncardiac chest pain by analysis of medical history and also to assess the relationship between coronary risk factors and vasospastic angina.

\section{Patients and Methods}

The subjects were 70 patients who visited our hospital with the chief complaint of chest pain at rest. We analyzed 59 (30 men and 29 women) of these 70 patients, who underwent diagnostic cardiac catheterization. On the day of admission, we gave each patient a questionnaire on the duration, provocation of the chest pain, relief, location of pain other than the chest, additional symptoms and the time at which the pain tended to occur (Table 1). If the chest pain was relieved by sublingual nitroglycerin within a few minutes, we defined it as "nitroglycerin effective". We also examined coronary risk factors from laboratory test, life history, and physical examination. The coronary risk factors we examined in this study are listed in Table 2. Before angiographic study all but one underwent an exercise test.

After written informed consent was obtained, all medications. except for sublingual nitroglycerin as needed, were stopped at least 48 hour before coronary angiography. Using Judkins technique, we performed diagnostic coronary angiography in the fasting state. A bipolar electrode catheter was

From the Department of Cardiology, Bibai Rosai Hospital, Bibai, *Sapporo Health Promotion Center, Sapporo and **the Department of Cardiology, Hokkaido University School of Medicine. Sapporo

Received for publication January 6, 1997: Accepted for publication June 10, 1997

Reprint requests should be addressed to Dr. Tadafumi Nanbu, the Department of Cardiology, Bibai Rosai Hospital, East 4 South 1, Bibai, Hokkaido 072 
inserted into the right ventricular apex through the femoral vein and connected to the temporary pacemaker. The pacing rate was 40 to 50 set per minute and the image tube was kept constant relative to the heart. Acetylcholine was administrated by left intracoronary injection over 20 seconds in titrated increments of $20,50,100 \mu \mathrm{g}$ diluted in $5 \mathrm{ml}$ of warm normal saline. The left coronary arteriography was performed when ST segment changes or chest pain occurred, or 1 and 3 minutes after each injection. Administration of acetylcholine into the right coronary artery was done in incremental doses of $20,50 \mu \mathrm{g}$ and right coronary arteriography was performed in the same way. $\mathrm{Pa}$ tients were asked to report any symptoms and whether the pain was identical to the spontaneous attack of chest pain. After the study, $2 \mathrm{mg}$ of isosorbid dinitrate was administrated into each coronary artery and coronary arteriography was again performed to exclude organic stenosis. Transarterial blood pressure and a 12-lead electrocardiogram were monitored continuously throughout the study, and the electrocardiogram was recorded at $25 \mathrm{~mm} / \mathrm{sec}$, when $\mathrm{ST}$ segment changed or after 1 and 3 minutes of acetylcholine injection.

Coronary spasm was defined as severe vasoconstriction associated with an attack of chest pain identical to spontaneous attack and/or ST segment changes on electrocardiogram (ECG) $(2,3)$. The diagnosis of vasospastic angina was made if the subject had spontaneous attacks of chest pain associated with

Table 1. Chest Pain Enquiry in the Medical Interview*

\begin{tabular}{|c|c|c|c|}
\hline Duration & $\begin{array}{l}\text { Less than } \\
1 \text { min }\end{array}$ & $\begin{array}{l}\text { More than } \\
20 \text { min }\end{array}$ & \\
\hline Provocation & Effort & $\begin{array}{l}\text { Temperature } \\
\text { Changes }\end{array}$ & \\
\hline $\begin{array}{l}\text { Location } \\
\text { Relief }\end{array}$ & $\begin{array}{l}\text { Retrosternal } \\
\text { Nitroglycerin }\end{array}$ & Left submammary & Back \\
\hline $\begin{array}{l}\text { Accompanying } \\
\text { symptoms }\end{array}$ & $\begin{array}{l}\text { Shortness of } \\
\text { breath }\end{array}$ & Cold sweat & Near syncope \\
\hline $\begin{array}{l}\text { Time to be } \\
\text { clustered }\end{array}$ & Early morning & Midnight & \\
\hline
\end{tabular}

*All of the answers were obtained by checking yes or no.
ST segment elevation without stenosis of more than $75 \%$ of luminar diameter or was proved test positive for coronary spasm.

\section{Statistical analysis}

The comparisons of two mean values of continuous variables were made by unpaired t-test. Differences in the prevalence of categoric risk factors and history information were tested by chi-square test. Multivariate analyses of coronary risk factors and history information were performed by multiple logistic regression. All analyses were performed using SPSS software (SPSS 4.0J, SPSS Japan Inc.).

\section{Results}

\section{Vasospasm provocation by acetylcholine}

Coronary spasm was induced in 26 patients. Of these 26 patients, multivessel coronary spasm was induced in 3 patients. Five patients had attacks of chest pain associated with ST segment elevation on electrocardiogram before the study. Coronary spasm associated with organic stenosis of coronary artery was induced in two patients. One case had left circumflex artery spasm with stenosis of the diagonal branches of greater than $90 \%$ and another had right coronary artery spasm with stenosis of the right coronary artery of greater than $75 \%$. Chest pain identical to the spontaneous attack without vasoconstriction was not induced in any patients.

\section{Coronary risk factors and medical history}

The average levels of coronary risk factors are shown in Table 2, and the strength of risk factors for vasospastic angina analyzed by multiple logistic regression is shown in Table 3 . The male gender was an independent predictor for vasospastic angina. Classic coronary risk factors such as plasma lipid levels or history of hypertension were not independent factors.

The relation of medical history and vasospastic angina is shown in Table 4, and the strength of each information derived from history is shown in Table 5. Univariate analysis showed that the chest pain accompanied by cold sweat and one occur-

Table 2. Average Level of Coronary Risk Factors in Each Group

\begin{tabular}{lccc}
\hline Risk factor & $\begin{array}{c}\text { Vasospastic angina } \\
(\mathrm{n}=26)\end{array}$ & $\begin{array}{c}\text { Non-cardiac chest pain } \\
(\mathrm{n}=33)\end{array}$ & p-value \\
\hline Age $(\mathrm{yr})$ & $57.2 \pm 9.7$ & $60.9 \pm 13.6$ & 0.29 \\
Male sex & $69 \%$ & $26 \%$ & 0.02 \\
Total cholesterol (mg/dl) & $191 \pm 32$ & $189 \pm 42$ & 0.83 \\
High density lipoprotein cholesterol (mg/dl) & $45 \pm 14$ & $47 \pm 13$ & 0.74 \\
Triglyceride (mg/dl) & $118 \pm 55$ & $118 \pm 59$ & 0.99 \\
Hypertension & $61 \%$ & $52 \%$ & 0.35 \\
Never smoked & $40 \%$ & $65 \%$ & 0.09 \\
Body mass index $\left(\mathrm{kg} / \mathrm{m}^{2}\right)$ & $24.8 \pm 2.7$ & $27.2 \pm 3.2$ & 0.69 \\
Diabetes & $26 \%$ & $13 \%$ & 0.23 \\
\hline
\end{tabular}

Data are shown as mean \pm SD or percent of subjects. 


\section{NANBU et al}

ring in the early morning were discriminating information. The effect of nitroglycerin was also a significant variable. But the duration, the precipitating factors and the location of chest pain were not significant variables. However, no variables in history information were significant by multiple logistic regression, although early morning occurrence tended to be significant $(\mathrm{p}=0.078)$.

\section{Discussion}

Risk factors for coronary artery disease (CAD) have been well established and it has become possible to reduce the incidence of CAD by modifying a given risk factor. For vasospastic angina, it is not well known whether the same risk factors for CAD can be applied. In this study, we demonstrated that one clinical feature is important in differentiating vasospastic angina from noncardiac chest pain, that is male sex. Our data suggests that purported protection of women from CAD may

Table 3. The Strength of Coronary Risk Factors

\begin{tabular}{lcc}
\hline Risk factor & Coefficient & p-value \\
\hline Male sex & 3.28 & 0.01 \\
Hypertension & -0.79 & 0.37 \\
Diabetes & 0.75 & 0.52 \\
Never smoked & -0.36 & 0.59 \\
Body mass index & 0.11 & 0.45 \\
Triglyceride & -0.01 & 0.24 \\
Total cholesterol & 0.01 & 0.51 \\
HDL cholesterol & 0.01 & 0.64 \\
Age & -0.01 & 0.89 \\
\hline
\end{tabular}

In the logistic regression we assigned noncardiac pain as 0 and vasospastic angina as 1 . extend to vasospastic angina.

A large percentage of patients with Printzmetal's angina is reported to be a heavy smoker. On the other hand, our results showed that cigarette smoking was not significantly related to vasospastic angina. One reason for this is that only a small percentage $(19 \%)$ of patients were diagnosed as Printzmetal's angina. Another reason is that vasomotor tone is not only modified by cigarette smoking, but also influenced by many substances (4) or by autonomic nerve tone (5).

Our results demonstrated that chest pain in the morning, and the accompanying sweating is important in distinguishing vasospastic angina from noncardiac chest pain. The time that the pain tended to occur was similar to that of variant angina as

Table 5. The Strength of Each Variable Derived from Medical History

\begin{tabular}{lrr}
\hline Variables & Coefficients & p-value \\
\hline Cold sweat & 11.99 & 0.79 \\
Submammary & -8.54 & 0.94 \\
Early morning & 3.76 & 0.078 \\
Near syncope & 2.02 & 0.39 \\
Less than 1 min & 2.00 & 0.42 \\
SOB & 1.83 & 0.31 \\
Effort & -1.31 & 0.25 \\
Temperature & 0.91 & 0.71 \\
More than 20 min & 0.76 & 0.54 \\
Retrosternal & -0.75 & 0.54 \\
NTG effective & 0.52 & 0.43 \\
Midnight & -0.38 & 0.73 \\
Back & 0.30 & 0.86 \\
\hline
\end{tabular}

Data are shown as coefficients of each variables. In the multiple logistic regression we assigned noncardiac pain as 0 and vasospastic angina as 1. NTG: nitroglycerin, SOB: shortness of breath.

Table 4. Results of Medical Interview in Each Group

\begin{tabular}{lccr}
\hline Variables & $\begin{array}{c}\text { Vasospastic angina } \\
(\mathrm{n}=26)\end{array}$ & $\begin{array}{c}\text { Noncardiac } \\
(\mathrm{n}=33)\end{array}$ & $\mathrm{p}$-value \\
\hline More than $20 \mathrm{~min}$ & $32(\%)$ & $45(\%)$ & 0.34 \\
Less than 1 min & 8 & 9 & 0.92 \\
Effort & 32 & 54 & 0.12 \\
Temperature & 16 & 5 & 0.20 \\
Retrosternal & 58 & 33 & 0.09 \\
Submammary & 0 & 9 & 0.12 \\
Back & 13 & 14 & 0.86 \\
NTG effective & 63 & 9 & 0.01 \\
Midnight & 42 & 19 & 0.48 \\
Early morning & 71 & 19 & 0.008 \\
SOB & 12 & 0 & 0.55 \\
Cold sweat & 37 & 5 & 0.001 \\
Near syncope & 21 & 0.12 \\
\hline
\end{tabular}

Data are shown as percent of subjects. NTG: nitroglycerin, SOB: shortness of breath. 
previously reported (6). This suggests that threshold for vasospasm or threshold for anginal pain is lower in the early morning than at any other times of the day.

Among various accompanying symptoms, cold sweat was discriminating. Sweating may result from severe cardiac ischemia that increases adrenergic tone abruptly. Since noncardiac chest pain without obvious underlying etiology is generally non lethal, autonomic tone may not be disturbed.

We asked the patients whether the pain was retrosternal because the usual distribution of anginal pain is referral to all or part of the sternal region (7). In this study the location of the pain was not discriminating information. The reason for this unexpected result is uncertain. One possibility is that our population with noncardiac chest pain might include patients with esophageal pain. Indeed, it is reported that noncardiac chest pain includes the esophageal spasm or esophagitis caused by gastric reflux $(8,9)$. Esophageal pain radiates to the back frequently like angina pectoris. Therefore, it is important to always consider esophageal disorders in differentiating the etiology of chest pain.

Some of the history information, such as left mammary location and accompanying syncope did not reach a statistical significance, but it may be due to the relatively small number of cases included in the study. The duration of attacks of the pain was also not determinative. It may be difficult to measure the exact duration of the pain and there may be discrepancy between the "real" and the "subjective" duration of attacks.

Precipitating factors of effort angina such as effort or temperature were not predictive of vasospastic angina statistically. But one case with vasospastic angina developed anginal pain while lying on an electric warm carpet and one case while using a snow blower. These two circumstances were reproducible and were thought to be a precipitating factor. We must remember that precipitating factors are different in each case. And what is important is to find out whether there is a precipitating factor or not in each individual case.

We did not classify the type of pain because expressions of complaint about chest varied widely. Although the type of chest pain is very important information, the definition of the vague discomfort is ambiguous and we were not able to reliably analyze the type of chest pain in all patients.

\section{Study limitation}

A negative acetylcholine test does not necessarily rule out vasospastic angina in all cases. The sensitivity of acetylcholine for the induction of vasospasm in patients with variant angina is reported to be $90 \%$ (2), and is comparable to ergonovine. But the mechanism of induction of vasospasm is different with these two agents (10). There are cases: where the acetylcholine test is negative and the ergonovine test is positive (11). In addition, there may be the possibility that in patients with chest pain with a normal coronary arteriogram and no evidence of large vessel spasm, the cardiac pain is induced due to an abnormality of the smaller resistance vessels that are not visible angiographically.

Reference also should be made to the relation of chest pain and psychiatric disorders. Previous reports have demonstrated that the patients with chest pain and normal coronary arteries, in many cases, suffer from panic disorder and have high scores on depression and anxiety scales $(12,13)$. In our study, a 25year-old female who complained of recurrent chest pain was subsequently diagnosed as panic disorder. From the point of general practical view, the psychological aspect of non-cardiac chest pain is important, and psychological evaluation may influence the indication for cardiac catheterization.

In summary, this study shows that the classic risk factors for coronary heart disease do not appear to be of importance in elucidating the etiology of chest pain at rest. On the other hand, the medical history is important. Chest pain with cold sweat and/or in the early morning, especially among male patients is one of the most valuable pieces of information in distinguishing vasospastic angina from other causes of chest pain. Finally, our inability to find independent predictors among history information may be related to the sample size.

\section{References}

1) Sandler G. The importance of the history in the medical clinic and the cost of unnecessary tests. Am Heart J 100: 928, 1980.

2) Okumura $K$, Yasue $H$, Matsuyama $K$, Goto $K$, Miyagi $H$, Ogawa $H$. Sensitivity and specificity of intracoronary injection of acetylcholine for the induction of coronary artery spasm. J Am Coll Cardiol 12: 883, 1988.

3) Okumura K, Yasue H, Horio $\mathrm{Y}$, et al. Multivessel coronary spasm in patients with variant angina: a study with intracoronary injection of acetylcholine. Circulation 77: 535, 1988.

4) Forman MB, Oates JA, Robertson D, Robertson RM, Roberts LJ, Virmani $R$. Increased adventitial mast cells in a patient with coronary vasospasm. N Engl J Med 313: 1138, 1985.

5) Hoshio A, Kotake H, Mashiba H. Significance of coronary artery tone in patients with vasospastic angina. J Am Coll Cardiol 14: 604, 1989.

6) Waters DD, Muller D, Bouchard A. Circadian variation in variant angina. Am J Cardiol 54: 61, 1984.

7) Diamond GA. A clinically relevant classification of chest pain discomfort. J Am Coll Cardiol 1: 574, 1983 (letter).

8) Conte MR, Orzan F, Magnance M, et al. Atypical chest pain. Coronary or esophageal disease? Int J Cardiol 13: 135, 1986.

9) Cook DG, Shaper AG. Breathlessness, angina pectoris and coronary artery disease. Am J Cardiol 63: 921, 1989 (see comments).

10) Yokoyama M, Akita H, Hirata K, et al. Supersensitivity of isolated coronary artery to Ergonovine in a patient with variant angina. Am J Med 89: $507,1990$.

11) Suzuki $Y$, Tokunaga $S$, Ikeguchi $S$, et al. Induction of coronary artery spasm by intracoronary acetylcholine: comparison with intracoronary ergonovine. Am Heart J 124: 39, 1992.

12) Serlie AW, Erdman RA, Passchier J, Trijsburg RW, ten Cate FJ. Psychological aspects of non-cardiac chest pain. Psychother Psychosom 64: 62, 1995.

13) Potts SG, Bass CM. Psychological morbidity in patients with chest pain and normal or near-normal coronary arteries: a long-term follow-up study. Psychol Med 25: 339, 1995. 